\title{
Three-dimensional cadastre in creating an information base for a spatial model of a real estate object
}

\author{
Grittel Shevchenko ${ }^{1,{ }^{*}}$, Dmitry Gura ${ }^{1,2}$, Polina Moskvina ${ }^{1}$, Irina Popova $^{1}$, Georgiy Akopyan ${ }^{1}$ \\ ${ }^{1}$ FSBEI of HE Kuban State Technological University, 2, Moskovskaya str., 350072, Krasnodar, \\ Russia \\ ${ }^{2}$ FSBEI of HE Kuban State Agrarian University named after I.T. Trubilin, 13, Kalinina str., 350044, \\ Krasnodar, Russia
}

\begin{abstract}
The relevance of the research topic is that the improvement of the land and real estate market is one of the most important goals of the development of digital economy of the Russian Federation. In recent years, a number of regulatory documents have been adopted in the field of state cadastral registration and registration of real estate titles. Some elements of state development programs of the Russian Federation in the field of land and real estate management were also introduced. An analysis of the documents shows that the introduction of a three-dimensional spatial description of real estate in the unified state register of real estate is beginning gradually. Its purpose is to eliminate a number of problems associated with state cadastral registration of real estate objects located at different levels (above ground, ground, underground), as well as unique buildings and structures. Despite all the available options for accounting for three-dimensional models of real estate in the unified state register of real estate, in fact, their registration in cadastral works is not performed in Russia. This is caused by the lack of scientific and methodological justification for implementation of cadastral work on three-dimensional modeling of real estate objects, taking into account domestic characteristics.
\end{abstract}

\section{Introduction}

The aim of the study is to consider and develop methods for introducing threedimensional cadastre technologies (3D cadastre) using an example of a real estate object located in one of the cities of the Russian Federation. In accordance with the goal, the following tasks can be formulated:

- analyze the shortcomings of the existing cadastral system in the Russian Federation;

- study the experience of creating a three-dimensional cadastre abroad;

- consider the procedure for creating an information base on the spatial model of a real estate object as part of the generated three-dimensional cadastre;

\footnotetext{
* Corresponding author: grettel@yandex.ru
} 
- identify the advantages and disadvantages of the formation of an information base on the spatial model of the real estate object as part of the generated three-dimensional cadastre.

In $[1,2,3]$, issues of the analysis of the advantages and disadvantages of existing threedimensional cadastral systems and the possibility of their functioning are considered.

Land and other real estate objects are almost always registered and provided as a twodimensional object. Nowadays, in most countries of the world, land plots are depicted on a plane. But, despite this, growth of population and constant real estate development require the introduction of other rules and requirements. It is worth considering that today construction is carried out not only above the ground, but also under it. That is why the cadastral system should objectively reflect the existing situation. Therefore, the question arises of the creation and implementation of a new registration system for complex objects, such as: tunnels, underground parking, various utility systems, etc.

The need to implement a $3 \mathrm{D}$ real estate cadastre is considered by each country in its own way. Over time, each owner comes to understand bias of the current system of registration of three-dimensional objects. For example, it is difficult to distinguish a plot of land where the boundaries of one property actually end and another ownership begins, while the plots are located one above the other (pipeline and private developer).

There is a need to register such real estate as:

- underground facilities (parking lots, tunnels);

- underground infrastructure (metro lines);

- structures located one above the other;

- underground engineering facilities (sewers, various cables);

- mining.

The problem is the existing system of property registration, which needs to be further developed. Its new three-dimensional model should be created, allowing to keep records in layers, and not on the plane.

\subsection{Analysis of the problem}

\subsubsection{Difficulties in using a $2 D$ cadastral system}

Nowadays, the system of the Unified State Register of Real Estate is based on a twodimensional representation of objects, including land, buildings, structures. However, the existing approach does not cover all situations in the real three-dimensional world, which causes problems in cadastral registration and registration of rights for a number of objects, for example:

a) Difficulties of registration and cadastral registration of multilevel complexes, including real estate owned by various owners. A single land plot registered at the same address at different levels in height may include real estate owned (or used on other legal grounds) by various individuals and legal entities. Lack of accurate information on vertical division can lead to conflict situations in the determination of rights and property disputes;

b) Registration and display in the cadastre of underground buildings and structures (underground parking lots, metro stations, tunnels (metro, automobile, railway), etc.) located under the real estate objects (land, buildings, structures) of other owners;

c) Registration and cadastral registration of elevated structures (crossings, bridges, etc.);

d) Registration and cadastral registration of underground and aboveground infrastructure, including engineering networks, utility systems (pipelines, cables, etc.). Moreover, objects can cross many land plots of different owners. The lack of information about the exact location of such objects causes difficulties. Existing data is located in 
various registries and databases, which makes it difficult, time consuming, and often makes it impossible to obtain them;

e) For multi-apartment residential complexes: in fact, the right to the area is registered, and not to the entire volume of premises. There is no possibility of determining the owner's rights to the external space around a residential building or premises.

Three-dimensional models replace traditional forms of presenting data about the world. This happened due to the development of geodetic equipment, the emergence of unmanned aerial vehicles, the improvement of existing software, digital technology and more. The use of three-dimensional modeling made it possible to develop a number of areas (construction, cartography, cadastre, etc.). For example, thanks to this, designers can take into account errors in the construction of buildings of the most complex form even at the stage of project development, extract all the necessary drawings of the object online (BIM technology).

The Unified State Register of Real Estate as an information system has the most complete and reliable information about recorded and registered real estate. The use of BIM-technologies allows obtaining a three-dimensional model of an object with all attribute data, which subsequently greatly simplifies the process of accounting and registration of such objects in the cadastre system [4].

\subsubsection{Foreign experience in creating a three-dimensional cadastre}

Nowadays, the three-dimensional cadastre system is practiced in most countries. It allows, achieving a high degree of fairness of taxation of property; secondly, increasing guarantees for the rights of property owners; thirdly, the constant updating of databases will increase the relevance of the information used.

Features of 3D cadastre:

the use of a huge number of aboveground and underground sections;

more rational use of land sites.

After analyzing the implementation of the three-dimensional cadastre abroad, we can conclude that due to the widespread use of automated systems in the design of buildings, the basis for its implementation will primarily be three-dimensional GIS [5,6]. Figure 1 shows an example of a three-dimensional terrain model.

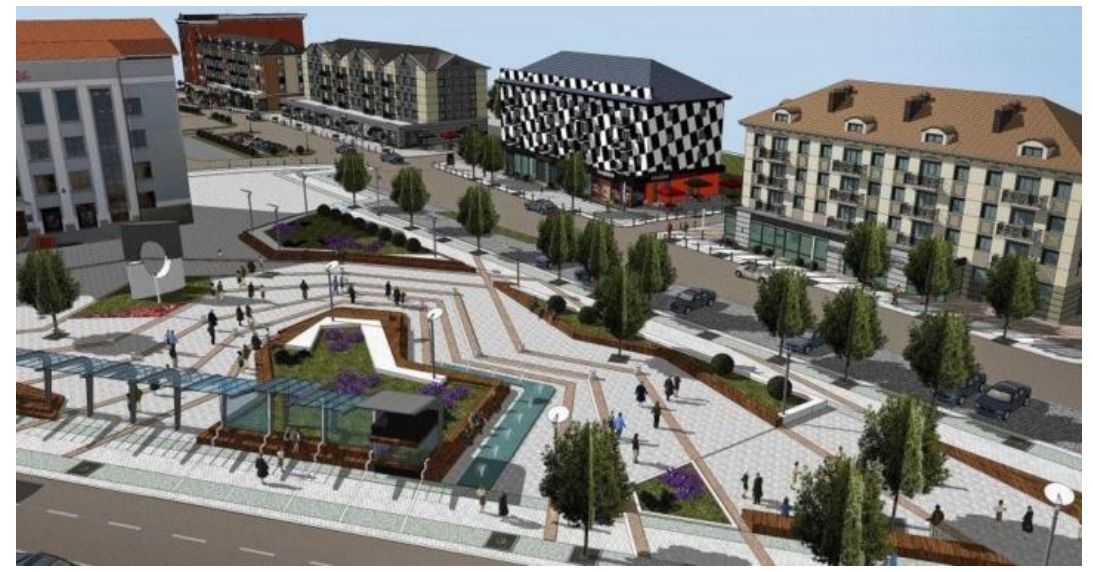

Fig. 1. Three-dimensional terrain model.

\subsubsection{Examples of cadastral systems in Norway}


In Norway, they began to build road tunnels that are laid under a land plot without notifying the owner about it, but, despite this, the issue of this right can only be resolved by concluding an agreement with the land owner (this is a contradiction to ourselves). Everyone knows that the description of the boundaries of the land plot is carried out in a two-dimensional cadastre, but the restrictions on the $\mathrm{Z}$ axis (up or down) are not taken into account, which is why Norway has introduced three-dimensional space into the cadastre.

In Norway, in addition to the standard information provided in the real estate cadastre, object codes (identification, coordinate) that connect or localize groups of different geographical data with each other are also used.

Also, the country has one of the well-known systems - GAB, which combines all the provided cadastral information. Its three main indicators are addresses, buildings and land plots. The cadastre of Norway was developed by the Oslo municipality and the Land Registry. They created a cadastre that even covers three-dimensional objects. In 1987, this cadastral system was approved and received the name "Oslo Method" $[7,8]$.

\subsubsection{Oslo experience with $3 D$ cadastre}

The entire land of the municipality is divided into fixed numbers of large territories, each of which is assigned a main registration number. These territories are then divided into sections and numbered in order. Within the municipality, the site is uniquely identified by the territory and its number - only eight digits. In order to identify the municipality, four more numbers are added at the national level.

The city of Oslo is divided into approximately 250 territories (regions). The underground area is identified as well as on the surface, but 300 is added to it. The number starts with one. This gives each underground site a clear definition of location in relation to the property on the surface. Numbers from $601-900$ are reserved for sites located above the ground $[7,8]$.

\section{Materials and methods}

To create a 3D cadastre, it is necessary to collect information about the spatial position of objects. Such data can be obtained using aerial photography and laser scanning methods, in particular, underground scanning.

Three-dimensional laser scanning is a filming system measures the distance from the scanner to the surface of the object with a high speed (starting from several thousand, ending with a million dots per second), registers the corresponding directions (vertical and horizontal angles), and subsequently forms a three-dimensional image (scan) in the form of a "point cloud" [9].

Let us consider the procedure for creating an information base for a real estate object modeled on the basis of ground-based laser scanning. The implementation of the work on creating an information model is presented in simplified form in Fig. 2.

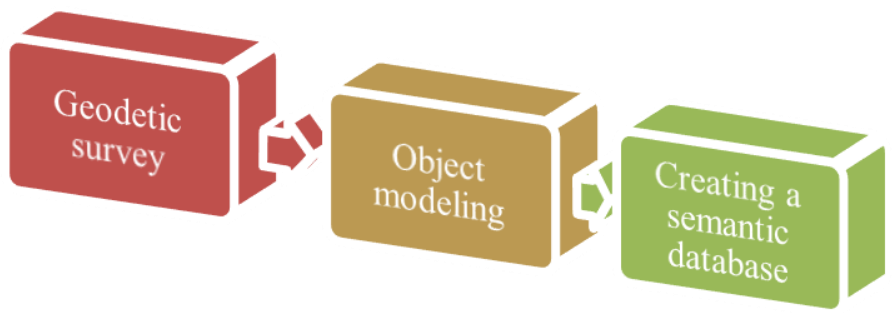

Fig. 2. Types of work for creating an information model. 
For modeling, the building was chosen in the city of Krasnodar, which is shown in Fig. 3.

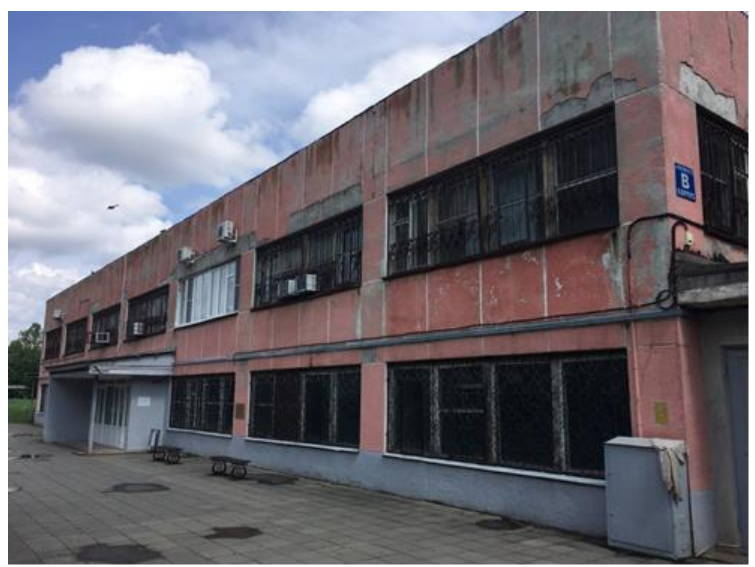

Fig. 3. Modeling object.

The location of the building in the cadastral quarter is shown in Fig. 4.

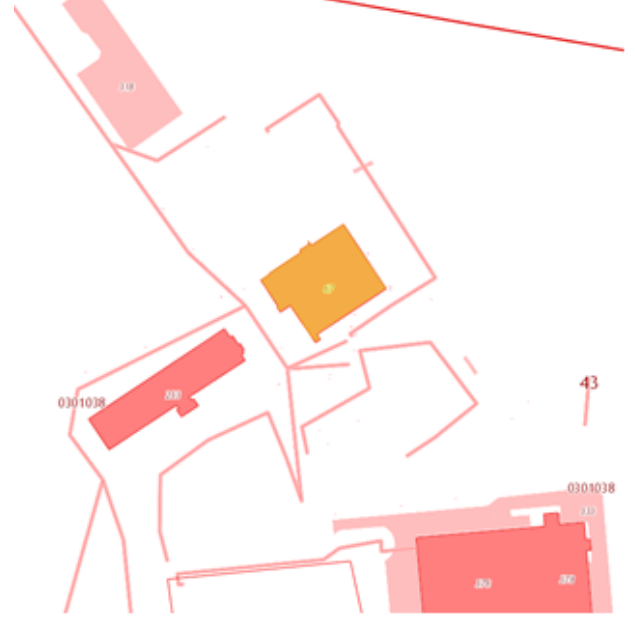

Fig. 4. Location of the object on the public cadastral map.

The real estate object is a two-story non-residential building with a total area of 3104.3 $\mathrm{m} 2$.

- Creating a 3D model is carried out in several stages:

- Uploading raw data to Cyclone software;

- Registration of scans in Cyclone Register;

- Object modeling (creation of three-dimensional drawings);

- Creating a semantic database.

A point cloud obtained from a ground-based laser scanner is imported into Cyclone software, creating a new project. Further on, scans are registered using these points.

Scanning was carried out with a ground-based laser scanner Leica ScanStation C10. The survey was carried out in two stages: from the ground, and on the roof. In total, 24 points of view of the device (station) were required, 12 for each stage.

Registration was performed by visual stitching. To perform visual stitching, it is necessary to overlay clouds from two stations on top of each other, connecting common places. First, the stations are adjusted horizontally, then vertically. This method does not 
require the placement of control points on the scan object. It is also necessary that not only the object itself be scanned, but also as much details around it as possible. For this, during field work, scanning is usually performed so that the survey stations are located at a distance of no more than 3-5 m from each other. This will improve the quality of stitching, since with insufficient informational content of the clouds, it is not possible to be sure of the correct registration.

The result of registering scans is a single point cloud that needs to be processed. The processing includes the removal of unnecessary points, as well as the removal of noise that occurs during scanning. Now it is possible to start modeling the prepared point cloud (Fig. $5)$.

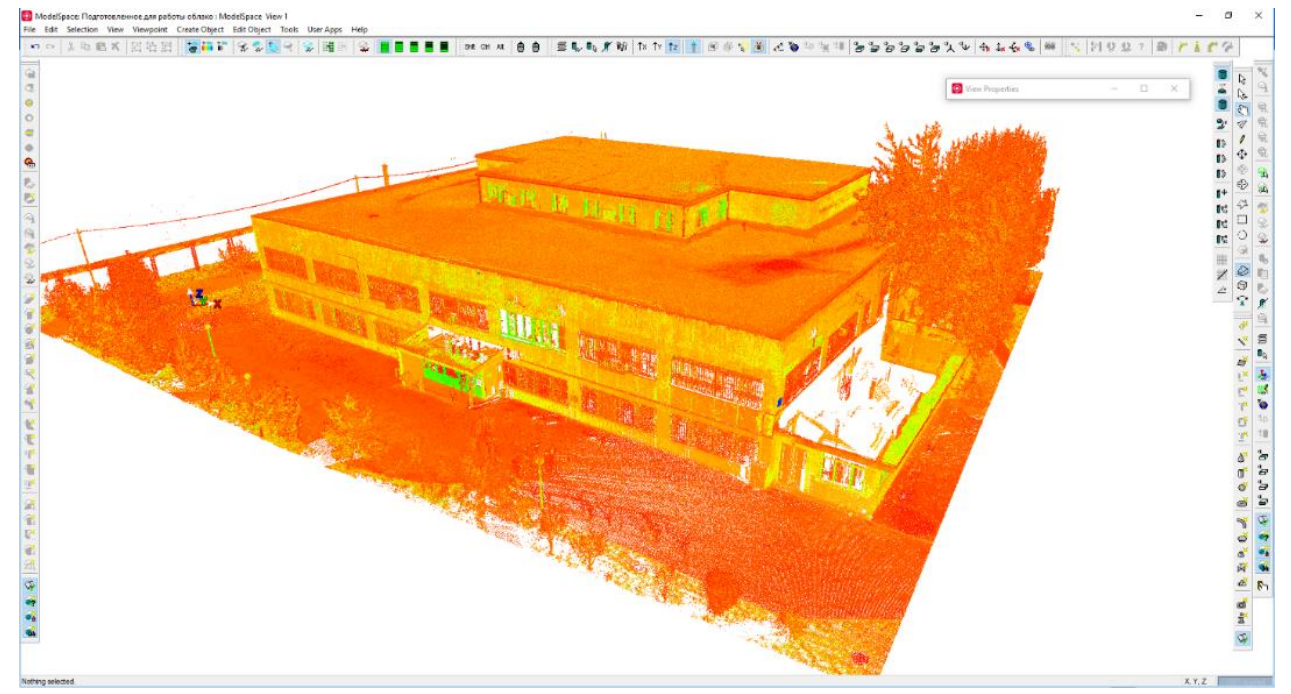

Fig. 5. Point cloud of the real estate object.

Further, using the functions of creating surfaces, the facade of the object is modeled. Create object $>$ Region grow $>$ Patch, choosing a point on the facade, the program will simulate a wall in semi-automatic mode. (Fig. 6)

Object modeling was performed in Cyclone 9.4 software.

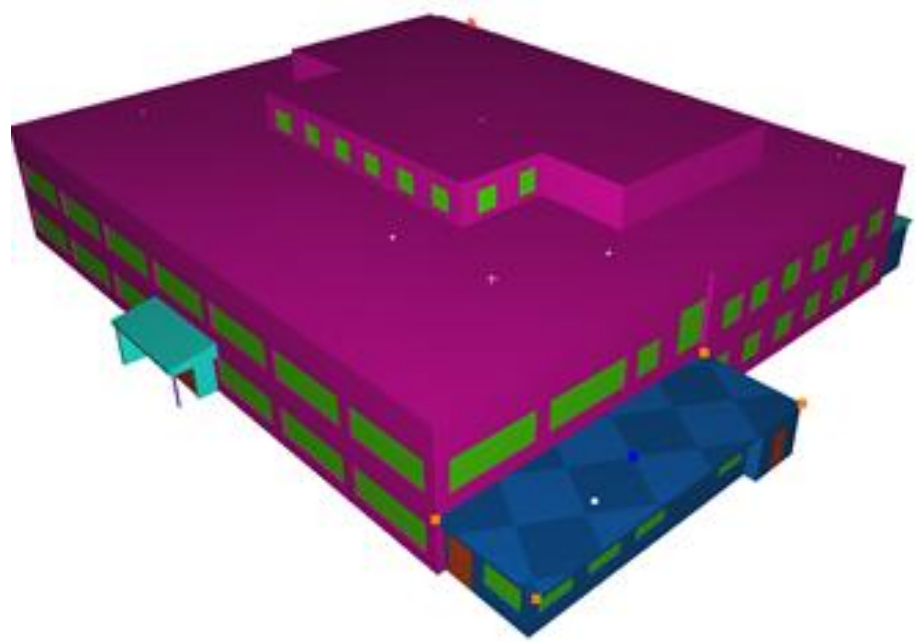

Fig. 6. 3D model of the real estate object. 
Creating a 3D model is carried out in several stages:

- uploading raw data to Cyclone software;

- registration of scans in Cyclone Register;

- object modeling (creation of three-dimensional drawings);

- creating a semantic database, which reflects cadastral information about the modeled real estate object.

To create a semantic database, the necessary information was collected about the real estate object, including cadastral information received from Russian Federal Service for State Registration, Cadastre and Cartography (Rosreestr).

The table of attributes is shown in Figure 7.

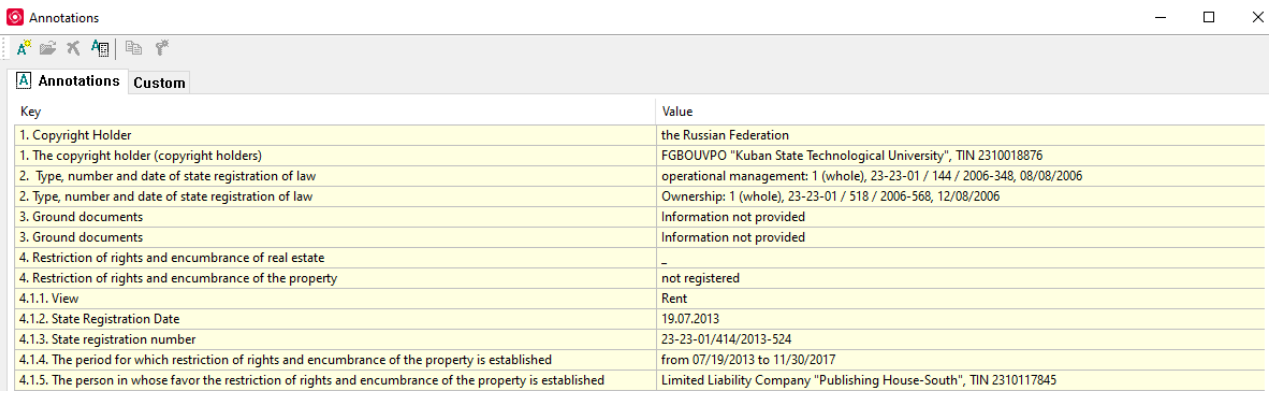

Fig. 7. The table of attributes.

Thus, an information base was obtained about the real estate object with the reflection of the necessary cadastral information (Fig. 8).

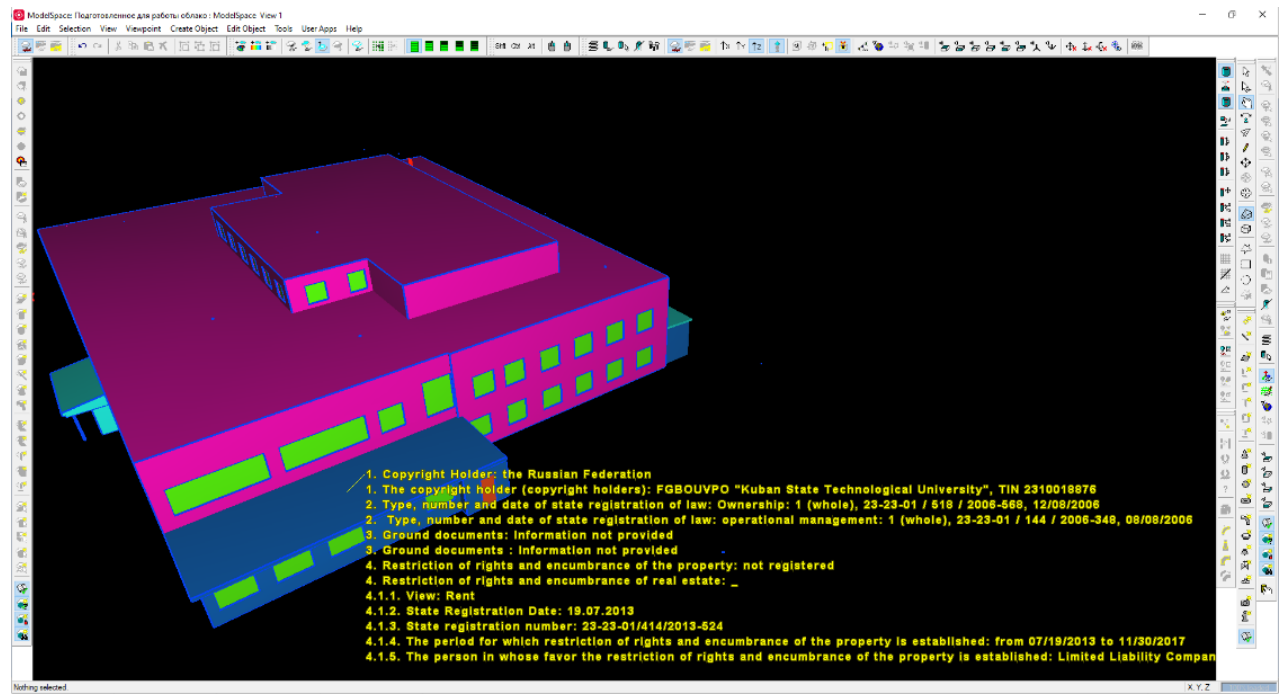

Fig. 8. Cadastral information for the modeled real estate object.

\section{Results}

During the study, information was collected on the real estate object, which is required to create a semantic base. Field work was carried out to scan the building, followed by data processing and modeling using a point cloud in Cyclone software. Based on the obtained data, a unified semantic base for the real estate object was compiled, during the creation of 
which some shortcomings were identified: the formation of a full-fledged threedimensional cadastre system in the Russian Federation is currently impossible due to the fact that the information contained in the Unified State Register of Real Estate does not take into account three-dimensional coordinates of the objects.

\section{Discussion}

The introduction of 3D cadastre technology will require the solution of various technological issues, and also research and changes in the regulatory framework of cadastral activities. To create and form this system, it is necessary to develop methods for measuring real estate objects in order to obtain their model and requirements for filling the semantic base for them. It is also important to develop a form of new cadastral documents for a real estate object, such as a new technical plan and, accordingly, requirements for its preparation, the composition of the information contained therein, taking into account the data that a three-dimensional model can give us [10-13].

Creating an information base on a spatial model of a real estate object, it is necessary to develop and implement an adequate three-dimensional geographic information system, which is the basis for the full-fledged creation of a three-dimensional cadastre in Russia.

Such a GIS will combine traditional operations when working with databases with the advantages of full visualization and geographical (spatial) analysis, which the map provides. This feature allows getting unique opportunities for the use of GIS in solving a wide range of tasks that are associated with the assessment of events, predicting their likely consequences, planning their solutions.

Nowadays, many professional GISs are widely used in the professional environment, such as Vertical Mapper 3.5 (three-dimensional modeling for MapInfo GIS), GeoDraw, GEO + CAD, Bentley PowerMap, OziExplorer - 3D and others. In order to form a unified approach and the basis for the development of a three-dimensional cadastre, it is necessary to conduct an extensive analysis of existing systems and develop a new one, which is most optimal for the present conditions and takes into account existing advanced technologies [14].

One of the most difficult tasks is to amend the regulatory framework for the most effective implementation of three-dimensional cadastre tools. Rosreestr is currently developing proposals for the Ministry of Economic Development to amend the Civil and Land Codes, the Law on Registration, as well as a number of other documents regulating the real estate market [15]. Changes in legislation will lead to the creation of new work formats for participants in the real estate market. For example, home buyers will have the opportunity to buy not only the area, but also the view from the apartment's window, since the 3D cadastre allow adding the amount of air that separates the apartment's windows from the sea line. The developer, planning to erect a multi-story building in front of the house, will be required to buy this object. Thanks to three-dimensional models, a cadastral valuation will be carried out based on the market price, since now the objects located nearby can vary in price several times. In order for the proposed three-dimensional model to function effectively, the work on creating the existing two-dimensional cadastre must be completed. While it is still at the reform stage, and the Unified State Register of Real Estate has not enough information, many real estate objects remain unaccounted for in accordance with all requirements of the law [15-21].

\section{Conclusion}


The cadastre in Russia is associated with a number of problems that need to be resolved in order to accept three-dimensional reality. One of the main issues in our country is the legal component of the 3D cadastre. The legislation of the Russian Federation in the field of state registration of rights to real estate and transactions with it, as well as state cadastral registration does not contain references to $3 \mathrm{D}$ objects, at the same time there are no obstacles to the registration of such objects. There is the lack of direct communication between Rosreestr and construction and architecture authorities in the cadastre of the Russian Federation. Nowadays, the use of three-dimensional technologies in Russia is carried out only in a number of projects for the construction of objects of national importance (Olympic facilities, sports arenas for the 2018 World Cup, etc.).

Theoretically, separate three-dimensional models of real estate objects can already be taken into account and registered in the Unified State Register of Real Estate. However, the conditions for storing and issuing such models from a single information environment have not been created, which significantly slows down the pace of their implementation in the cadastre. The transition to a three-dimensional cadastre of real estate will improve the cadastral registration and registration of objects. Moreover, this will make it possible to address issues of territorial planning in cities, the improvement of urban areas, the development of investment construction, ensuring environmental, sanitary and epidemiological safety of the environment, and many other aspects related to the development of modern urban areas.

\section{Acknowledgement}

The study was financially supported by the Russian Foundation for Basic Research and the Administration of the Krasnodar Krai of the Russian Federation as part of research project No. 19-48-233020 "Research on the possibility of using a complex of three-dimensional laser scanning for monitoring and ensuring the safety of infrastructure facilities in the city of Krasnodar and the Krasnodar Krai".

\section{References}

1. Ch. Griffith-Charles, M. Sutherland, Land Use Policy, 104372 (2019)

2. P. Oosterom, Computers, Environment and Urban Systems 40, 1-6 (2013)

3. N.V. Gatina, T.A. Kadetova, Journal of Economics and Social Sciences 14(14), 76-81 (2019)

4. Final report on the Russian-Dutch project "Creating a model of three-dimensional real estate cadastre in Russia" (G2G10/RF/9/1)

5. N.Sh. Khayrudinova, Geo-Siberia-2011 Scientific Congress, Economic development of Siberia and the Far East. Economics of nature management, land management, forest management, real estate management (2011)

6. T.A. Gura, D.I. Turov, D.A. Gura, G.G. Shevchenko, Scientific works of the Kuban State Technological University 4, 297-308 (2017)

7. A.I. Yambars, Student electronic scientific journal 20(40) (2018)

8. H. Onsrud, Computers, Environment and Urban Systems 27(4), 375-382 (2003)

9. Russian Federal Service for State Registration, Cadastre and Cartography in the Krasnodar Krai, http://www.to.23.rosreestr.ru/news/media/1420745/

10. L. Cheng, S. Chen, X. Liu, H. Xu, Y. Wu, M. Li, Y. Chen, Sensors 18, 1641 (2018)

11. B. Yang, Z. Dong, F. Liang, Y. Liu, ISPRS J. Photogramm 113, 43-58 (2016) 
12. J. Tekavec, M. Ferlan, A. Lisec, Geodetski Vestnik 62, 249-278 (2018) 10.15292/geodetski-vestnik.2018.02.249-278

13. J. Stoter, S. Ho, F. Biljecki, Considerations for a contemporary $3 D$ cadastre for our times (2019) XLII-4/W15.81-88.10.5194/isprs-archives-XLII-4-W15-81-2019

14. E.A. Pavlova, Molodoy Uchyony (Young scientist) 8, 40-42 (2012)

15. A.V. Osennyaya, I.S. Gribkova, Theoretical basis of the cadastre of built-up territories (Krasnodar, 2012)

16. N. Vatin, N. Lavrov, G. Loginov. MATEC Web of Conferences. 2016. 73. DOI:10.1051/matecconf/20167301006.

17. O. Kalinina, V. Suschenko, V. Shchegolev, S. Barykin. Proceedings: MATEC Web of Conferences. Volume 193. P. 05063. (2018) DOI: 10.1051/matecconf/201819305063

18. S. Barykin, A. Kobicheva. Proceedings: MATEC Web of Conferences. Volume 170. P. 01020. (2018) DOI: 10.1051/matecconf/201817001020

19. I. Krasyuk, Y. Medvedeva, V. Baharev, G. Chargaziya. Proceedings: IOP Conference Series: Materials Science and Engineering. P. 012124. (2019) DOI: 10.1088/1757899X/497/1/012124

20. I. Krasyuk, T. Kirillova, V. Bakharev, B. Lyamin. Proceedings: IOP Conference Series: Materials Science and Engineering. P. 012125. (2019) DOI: 10.1088/1757$899 X / 497 / 1 / 012125$

21. S. Bozhuk, N. Krasnostavskaia, N. Pletneva, T. Maslova. IOP Conference Series: Materials Science and Engineering. 497 (1). P. 012. (2019) DOI: 10.1088/1757$899 X / 497 / 1 / 012115$ 